\title{
Optimization and assessment of a sequential extraction procedure for calcium carbonate rocks
}

\author{
Janin Scheplitz • Sarah Koopmann • \\ Henning Fröllje • Thomas Pichler 10
}

Received: 27 January 2021 / Accepted: 12 July 2021 / Published online: 16 August 2021

(C) The Author(s) 2021

\begin{abstract}
Sequential extraction analyses are widely used for the determination of element speciation in sediments and soils. Typical sequential extraction protocols were developed to extract from lowcarbonate samples and therefore are not necessarily suitable for high-carbonate samples. In this study, we tested increased reagent to sample ratios to adjust an existing sequential extraction procedure to analyze high- $\mathrm{CaCO}_{3}$ samples with concentrations ranging from 70 to above $90 \%$. Complete dissolution of the $\mathrm{CaCO}_{3}$ phase, and a higher extraction efficiency of manganese associated with the carbonate phase, was achieved when using four times the original reagent to sample ratio in the 2 nd extraction step. This increase of reagent did not compromise the extraction of subsequent phases as shown by unaffected Fe concentrations in a low-carbonate sample. Hence, an essential outcome was that increasing the solution to sample ratio did not lead to the dissolution of other sedimentary phases, such as hydrous and crystalline iron oxides or sulfides. Thus, compared to other extraction protocols that use a lower reagent to sample ratio in the carbonate dissolution step, the new protocol
\end{abstract}

Supplementary information The online version contains supplementary material available at https://doi. org/10.1007/s10661-021-09300-x.

J. Scheplitz $\cdot$ S. Koopmann · H. Fröllje $\cdot$ T. Pichler $(\bowtie)$

Fachbereich Geowissenschaften, Universität Bremen,

Klagenfurter Str. 2-4, 28359 Bremen, Germany

e-mail:pichler@uni-bremen.de allowed the complete extraction of oxide and sulfide phases in the following extraction steps. Furthermore, the study demonstrated the benefit of replacing Naacetate with $\mathrm{NH}_{4}$-acetate to extract exchangeable ions and carbonates. We observed increased intensities for several analytes, i.e., trace metals such as Mo and As, due to less suppression of the analyte signal by $\mathrm{NH}_{4}$-acetate than by Na-acetate during analysis by inductively coupled plasma optical emission spectrometry (ICP-OES).

Keywords Sequential extraction analysis . Carbonate $\cdot$ Contaminant $\cdot$ Karst aquifer . Molybdenum $\cdot$ Arsenic

\section{Introduction}

Carbonate aquifers supply approximately 20 to $25 \%$ of the world's population with water (Ford \& Williams, 2007; Goldscheider et al., 2020). While they are generally great for water quantity, they can be problematic with respect to water quality. Already at minute degrees of karstification, rapid flow through larger voids can negate the purification properties that generally make groundwater a safe source of drinking water (e.g., Katz, 2004; McMahon et al., 2008). Hence, understanding water-rock interaction and the associated release of contaminants in carbonate aquifers is essential to evaluate and forecast possible contamination scenarios. The importance of investigations into carbonate aquifers concerning the 
release of pollutants, such as molybdenum (Mo) or arsenic (As), has been demonstrated (Jones \& Pichler, 2007; Katz et al., 2009; Lazareva et al., 2015; Pichler \& Mozaffari, 2015). Anthropogenic influences can play a critical role in this context, as shown in central Florida, where drilling activities led to the injection of oxygen-rich water into a deep, anoxic carbonate aquifer (Wallis \& Pichler, 2018). Consequently, through the induced oxidation of organic matter, large amounts of up to $4740 \mu \mathrm{g} / \mathrm{L}$ Mo and $371 \mu \mathrm{g} / \mathrm{L}$ As were released; both exceeding the World Health Organization mandated health-based threshold values for drinking water of $70 \mu \mathrm{g} / \mathrm{L}$ for Mo and $10 \mu \mathrm{g} / \mathrm{L}$ for As (Pichler et al., 2017; WHO, 2011).

An integral approach to understanding the mobility of trace metals in the shallow subsurface is sequential extraction analysis, which allows conclusions about the chemical bonding of elements in the aquifer matrix (e.g., Filgueiras et al., 2002). Combined with complementary methods such as batch experiments, mobilization processes of contaminants to ambient water can be estimated (e.g., Koopmann et al., 2019). The basic principle of the sequential extraction procedure of sediments or soils is the differentiation of the analytes' chemical bonding by step-wise extraction using different reagents. The choice of reagent depends on the particular research questions and the type of material under investigation. Based on the classic sequential extraction method of Tessier et al. (1979), some well-established extraction protocols were developed (e.g., Gleyzes et al., 2002; Quevauviller et al., 1994; Rauret et al., 1999; Sutherland \& Tack, 2002; Ure et al., 1993a). There have been approaches to extract metals from highcarbonate samples (Gleyzes et al., 2001; Orsini \& Bermond, 1993), but none was optimized for extraction from a dominantly calcium carbonate $\left(\mathrm{CaCO}_{3}\right)$ matrix. While the focus was often the extraction of As from different soils and sediments (e.g., Gleyzes et al., 2001; Keon et al., 2001; Price \& Pichler, 2005; Pichler \& Veizer, 2004; Romero et al., 2003; Van Herreweghe et al., 2003; Wenzel et al., 2001), only a few were optimized for the extraction of Mo (Aydin et al., 2012; Liang \& Zhu, 2016; Zemberyova et al., 2010).

Sequential extraction procedures were developed to extract from heterogeneous sediments and soils (e.g., Quevauviller et al., 1994; Tessier et al., 1979), generally consisting of carbonate, hydroxide, oxide, silicate, sulfate, and sulfide minerals. The difficulty of performing sequential extraction analyses of carbonate sediments is that they are relatively homogenous, consisting of mainly $\mathrm{CaCO}_{3}$ minerals, such as calcite and aragonite. Thus, although present at concentrations above $80 \%$, it is crucial that the carbonate phase is extracted in a discrete step and not as part of the following steps. Here, we present a modification of an established sequential extraction procedure originally developed by Hall et al. (1996) and Pichler et al. (2001) for the application to heterogeneous soils and sediments. The main objective of our study was to develop a sequential extraction procedure for carbonate-rich samples that guarantees the quantitative dissolution of calcium carbonate in a discrete carbonate-removal step. This is crucial for the extraction of potential contaminants (e.g., As, Mo) together with their associated host phases, since incomplete dissolution of carbonates has the potential to buffer the extraction of the target phases in the following extraction steps. Similarly, excess extraction solution may unintentionally attack oxide or sulfide phases. Hence, besides aiming for the complete dissolution of carbonates in a discrete step, an additional focus was to avoid compromising the subsequent extraction steps, particularly those of hydrous and crystalline iron oxides.

\section{Experimental}

Sample material

The optimization of the sequential extraction procedure was carried out using four $\mathrm{CaCO}_{3}$ sediment samples (C-90, C-68, C-78, C-74, Table 1) from two cores (DEP-1 and DEP-2) drilled in the municipality of Lithia in central Florida (Pichler \& Mozaffari, 2015; Pichler et al., 2017). The samples cover the Hawthorn Group, a lithostratigraphic unit of the Intermediate Aquifer System, which was deposited in a shallow marine to nonmarine fluvial depositional environment mainly during the Miocene. Detailed descriptions of the lithostratigraphy and hydrostratigraphy of the area can be found elsewhere (Katz et al., 2009; Miller, 1986; Pichler \& Mozaffari, 2015; Pichler et al., 2011). The samples were primarily chosen based on their $\mathrm{CaCO}_{3}$ contents, which were determined with a calcium carbometer and ranged from 68 to $90 \%$ (Table 1). In addition to the Floridian samples, a certified reference material 
Table 1 Samples used for the optimization of the sequential extraction procedure

\begin{tabular}{llllcc}
\hline Sample & Material & Origin/core & Lithology & $\begin{array}{l}\text { Depth } \\
(\mathbf{m})\end{array}$ & $\begin{array}{l}\text { CaCO } \\
(\%)\end{array}$ \\
\hline C-90 & Limestone & DEP-1 & Miocene, Hawthorn Group & 136 & 90 \\
C-68 & Limestone & DEP-1 & Miocene, Hawthorn Group & 152 & 68 \\
C-78 & Limestone & DEP-2 & Miocene, Hawthorn Group & 105 & 78 \\
C-74 & Limestone & DEP-2 & Miocene, Hawthorn Group & 112 & $1603-1605$ \\
PS-14 & Posidonia Shale & Rheden 6 Core 19 & Lower Jurassic, Toarcian & 14 \\
GBW-07120 & Limestone & GBW-07120 & Certified Reference Material & - & 92 \\
\hline
\end{tabular}

${ }^{\text {a }}$ S. Koopmann, unpublished data, samples provided by Wintershall Dea GmbH, Germany

GBW-07120 (China National Analysis Center) and a shale sample with approximately $14 \% \mathrm{CaCO}_{3}$ (PS-14) were analyzed as well (Table 1).

All samples were crushed in an agate mortar and subsequently ground to a fine powder in a planetary micro mill (Fritsch Pulverisette 7).

\section{Reagents}

All solutions were prepared using ultrapure water (18.2 M $\Omega$, Milli-Q). Analytical-grade Na-acetate $\left(\mathrm{NaCH}_{3} \mathrm{COO}\right.$; AppliChem, Germany), reagent-grade $\mathrm{NH}_{4}$-acetate $\left(\mathrm{NH}_{4} \mathrm{CH}_{3} \mathrm{COO}\right.$; Fisher Chemical, USA), ReagentPlus ${ }^{\circ}$-grade hydroxylamine hydrochloride $\left(\mathrm{NH}_{2} \mathrm{OH} \bullet \mathrm{HCl}\right.$; Sigma-Aldrich, Germany), and trace metal-grade acetic acid $\left(\mathrm{CH}_{3} \mathrm{COOH}\right.$; Fisher Chemical, USA) were used for the preparation of the extractants. Hydrochloric acid $(\mathrm{HCl})$ and nitric acid $\left(\mathrm{HNO}_{3}\right)$ were purified by sub-boiling from analytical-grade acids (Merck, Germany). Adjustment of $\mathrm{pH}$ was done using sub-boiled $\mathrm{HNO}_{3}$ and trace analysis supra-grade ammonia solution $\left(\mathrm{NH}_{4} \mathrm{OH}\right.$; Bernd Kraft, Germany).

Aqua regia digestion

To determine the total extractable element content in the samples, we followed a procedure based on the modified BCR method (Rauret et al., 1999; Sutherland \& Tack, 2002), where $10 \mathrm{~mL}$ aqua regia was added to 0.5 $\mathrm{g}$ of powdered sample and digested in a hot block. After being kept at room temperature overnight, the samples were heated to $120^{\circ} \mathrm{C}$ for $2 \mathrm{~h}$ under reflux, diluted with ultrapure water to $50 \mathrm{~mL}$ after cooling and subsequently filtered using in-vial filters (Environmental Express
Filter Mate, $6 \mu \mathrm{m}$ pore size). Before the measurements, the samples were further diluted 1:1 with ultrapure water to achieve a $10 \%$ acid matrix. Aqua regia digestion was done in triplicate for each sample. All samples were stored at room temperature until analysis.

Sequential extraction procedure

\section{Original method}

The first set of sequential extraction procedures were performed using a slightly modified version of the extraction procedure published by Hall et al. (1996) and Pichler et al. (2001) (Table 2). That procedure was considered the base for the adjustments for the high and variable carbonate contents of the samples. Other than in the original procedure, the multi-acid digestion to dissolve silicates and residuals was not considered necessary for this study. The sequential extraction was done in triplicate for each sample.

The extraction sequence was carried out using $0.5 \mathrm{~g}$ of sediment, which was weighed directly into centrifuge tubes, which also served as the reaction vessels. After each extraction, the samples were centrifuged for $15 \mathrm{~min}$, the extract decanted into a 50-mL polypropylene tube, filtered through a 0.45 $\mu \mathrm{m}$ pore size nylon filter, and acidified to $2 \% \mathrm{HNO}_{3}$. Before adding the next reagent, the residual sediment was washed and subsequently centrifuged twice with $5 \mathrm{~mL}$ ultrapure water. The fifth extraction step (sulfides/organic material) was done, as described in section "Aqua regia digestion." All samples were done in triplicate to control potential uncertainties in the extraction efficiency. 
Table 2 Slightly modified sequential extraction scheme based on Hall et al. (1996) and Pichler et al. (2001) (see section "Original method") adjusted to $0.5 \mathrm{~g}$ of sediment material

\begin{tabular}{|c|c|c|c|}
\hline Step & Phase & Reagents & Procedure \\
\hline 1 & Adsorbed/exchangeable & $10 \mathrm{~mL} 1.0 \mathrm{M} \mathrm{NaCH}_{3} \mathrm{COO}(\mathrm{pH} 8.2)$ & $2 \mathrm{~h}$ leach, $2 \times 5 \mathrm{~mL} \mathrm{H}_{2} \mathrm{O}$ rinse \\
\hline 2 & Carbonates & $10 \mathrm{~mL} 1.0 \mathrm{M} \mathrm{NaCH}_{3} \mathrm{COO}(\mathrm{pH} 5.0)$ & $2 \mathrm{~h}$ leach, $2 \times 5 \mathrm{~mL} \mathrm{H}_{2} \mathrm{O}$ rinse \\
\hline 3 & Hydrous iron oxides & $10 \mathrm{~mL} 0.25 \mathrm{M} \mathrm{NH}_{2} \mathrm{OH} \cdot \mathrm{HCl}$ in $0.25 \mathrm{M} \mathrm{HCl}$ & $2 \mathrm{~h}$ bath at $60^{\circ} \mathrm{C}, 2 \times 5 \mathrm{~mL} \mathrm{H}_{2} \mathrm{O}$ rinse \\
\hline 4 & Crystalline iron oxides & $15 \mathrm{~mL} 1.0 \mathrm{M} \mathrm{NH} \mathrm{NH}_{2} \mathrm{OH} \cdot \mathrm{HCl}$ in $25 \% \mathrm{CH}_{3} \mathrm{COOH}$ & $3 \mathrm{~h}$ bath at $90^{\circ} \mathrm{C}, 2 \times 5 \mathrm{~mL} \mathrm{H}_{2} \mathrm{O}$ rinse \\
\hline 5 & Sulfides/organic material & $10 \mathrm{~mL}$ aqua regia $\left(7.5 \mathrm{~mL} \mathrm{HCl}, 2.5 \mathrm{~mL} \mathrm{HNO}_{3}\right)$ & $\sim 12 \mathrm{~h}$ bath $\left(2 \mathrm{~h}\right.$ at $\left.120^{\circ} \mathrm{C}\right)$ \\
\hline
\end{tabular}

In preparation for chemical analysis, the extracts from steps 1 and 2 were diluted 1:2 with $2 \% \mathrm{HNO}_{3}$, and those of extraction step 4 were diluted 1:1 with 2 $\% \mathrm{HNO}_{3}$ to circumvent stability problems during the ICP-OES measurements that arise from high acetic acid/acetate matrix loads, as observed in preliminary measurements. All samples were stored at room temperature until analysis.

\section{Adjustments to the sequential extraction procedure}

The original sequential extraction procedure was modified to optimize the method for samples with high $\mathrm{CaCO}_{3}$ contents. We increased the reagent to sample ratio in the carbonate extraction step (step 2) to dissolve carbonates quantitatively while keeping the reagent to sample ratio constant in step 1 as well as in steps 3-5. As part of this adjustment, we lowered the sediment amount to $0.25 \mathrm{~g}$ to be able to increase the reagent to sample ratio with the available equipment (limitation to $20 \mathrm{~mL}$ solution). The adjustment of reagent to sample ratio was done using $\mathrm{Na}$-acetate and $\mathrm{NH}_{4}$-acetate in extraction step 2 (see below). Due to the excellent reproducibility in our first set of analyses, we refrained from performing those extractions in triplicate. Simultaneously, we replaced Na-acetate by $\mathrm{NH}_{4}$-acetate in steps 1 and 2 and compared the extraction efficiencies to avoid high sodium loadings during ICP-OES measurements. For both extraction solutions, the $\mathrm{pH}$ was kept at the original value of $\mathrm{pH}=8.2$ for step 1 and $\mathrm{pH}=5.0$ for step 2 (Tables 2 and 3). The changes to the sequential extraction procedure are summarized in Table 3. All the samples were stored at room temperature until analysis.

\section{ICP-OES analysis}

Elemental concentrations of $\mathrm{Ca}$ (analytical wavelength: $317.933 \mathrm{~nm}), \mathrm{Mg}(285.213 \mathrm{~nm}), \mathrm{Sr}(407.771$ $\mathrm{nm}), \mathrm{Fe}$ (238.204 nm), Mn (257.610 nm), As (188.979 $\mathrm{nm})$, and Mo $(202.031 \mathrm{~nm})$ were determined using the Optima 7300 DV inductively coupled plasma optical emission spectrometer (ICP-OES; Perkin Elmer). Instrumental setup and operational conditions are listed in Table 4. Calibration standards were prepared from $1000 \mathrm{mg} / \mathrm{L}$ single-element stock solutions (Inorganic Ventures, USA, and SPEX Certiprep, USA) and matrix-matched with the particular extraction step samples. Instrument blanks and procedural blanks were analyzed in addition to quality control standards. In-house tap-water and an artificial multi-element

Table 3 Modifications to the sequential extraction scheme shown in Table 2 and adjusted to $0.25 \mathrm{~g}$ of sediment material

\begin{tabular}{|c|c|c|c|}
\hline Step & Phase & Reagents & Procedure \\
\hline 1 & Adsorbed/exchangeable & 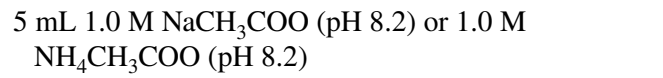 & $2 \mathrm{~h}$ leach, $2 \times 5 \mathrm{~mL} \mathrm{H}_{2} \mathrm{O}$ rinse \\
\hline 2 & Carbonates & $\begin{array}{l}10 \mathrm{~mL}, 15 \mathrm{~mL} \text {, or } 20 \mathrm{~mL} 1.0 \mathrm{M} \mathrm{NaCH}_{3} \mathrm{COO}(\mathrm{pH} 5.0) \\
\text { or } 1.0 \mathrm{M} \mathrm{NH}_{4} \mathrm{CH}_{3} \mathrm{COO}(\mathrm{pH} 5.0)\end{array}$ & $2 \mathrm{~h}$ leach, $2 \times 5 \mathrm{~mL} \mathrm{H}_{2} \mathrm{O}$ rinse \\
\hline 3 & Hydrous iron oxides & $5 \mathrm{~mL} 0.25 \mathrm{M} \mathrm{NH}_{2} \mathrm{OH} \cdot \mathrm{HCl}$ in $0.25 \mathrm{M} \mathrm{HCl}$ & $2 \mathrm{~h}$ bath at $60^{\circ} \mathrm{C}, 2 \times 5 \mathrm{~mL} \mathrm{H}_{2} \mathrm{O}$ rinse \\
\hline 4 & Crystalline iron oxides & $7.5 \mathrm{~mL} 1.0 \mathrm{M} \mathrm{NH}_{2} \mathrm{OH} \cdot \mathrm{HCl}$ in $25 \% \mathrm{CH}_{3} \mathrm{COOH}$ & $3 \mathrm{~h}$ bath at $90{ }^{\circ} \mathrm{C}, 2 \times 5 \mathrm{~mL} \mathrm{H}_{2} \mathrm{O}$ rinse \\
\hline 5 & Sulfides/organic material & $5 \mathrm{~mL}$ aqua regia $\left(3.75 \mathrm{~mL} \mathrm{HCl}, 1.25 \mathrm{~mL} \mathrm{HNO}_{3}\right)$ & $\sim 12 \mathrm{~h}$ bath $\left(2 \mathrm{~h}\right.$ at $\left.120^{\circ} \mathrm{C}\right)$ \\
\hline
\end{tabular}


Table 4 Instrument setup and operational parameters of the ICP-OES analyses

\begin{tabular}{ll}
\hline Nebulizer & MiraMist PEEK \\
\hline Spray chamber & Cyclonic glass \\
View mode & Radial and axial \\
RF power (W) & 1500 \\
Plasma gas flow (L/min) & 15.0 \\
Torch position & -2 \\
Auxiliary gas flow (L/min) & 1.0 \\
Nebulizer gas flow (L/min) & 0.8 \\
Pump rate (mL/min) & 1.5 \\
Rinse time (s) & 30 \\
Delay time (s) & 60 \\
Replicates per sample & 3 \\
\hline
\end{tabular}

standard independently prepared from single-element stock solutions were used to check for accuracy, precision, and instrument drift during measurements. For analysis of the samples and standards, $5 \mathrm{~mL}$ of each solution was transferred to $10-\mathrm{mL}$ PE vials and analyzed without further dilution using a standard sample introduction system (Table 4). All analyzed data were within the linear calibration range.

Instrument and procedural blanks were negligible for the analyzed elements in all extracted phases, and no instrument drift was observed during a daily run. Reproducibility of the analysis was checked by measurement of three replicates per sample having a deviation of generally $<2 \%$. Quality control standards agreed with the nominal values within an error of $<10 \%$. To assure the quality of the presented data, we do not report data for those measurements where the reproducibility (as relative standard deviation of signal intensities) of the ICPOES replicate analysis $(n=3$; Table 4$)$ had an error of $>10 \%$ (indicated as not determined (n.d.) in SI tables A2 to A5). This is typically the case for elements analyzed at very low signal intensities close to the blank intensity, i.e., elements with very low concentrations in the measurement solutions.

\section{Results}

Aqua regia digestions

The triplicate analyses were in good agreement, with an RSD of generally less than $5 \%$ for those elements with concentrations above the detection limit (Table A.1, Supplementary Information (SI)). The carbonate content calculated from the $\mathrm{Ca}$ concentration, assuming that all $\mathrm{Ca}$ was from $\mathrm{CaCO}_{3}$, agreed with the concentration determined with the carbometer (Tables 1 and A.1, SI). Furthermore, the carbonate content of the reference material GBW07120 calculated from the Ca analysis (91\%) agreed with the carbonate content determined with the carbometer $(91 \%)$ and carbonate content calculated from published $\mathrm{CaO}(51.1 \%)$ and $\mathrm{CO}_{2}(39.8 \%)$ values (China National Analysis Center). Overall, the results demonstrated that most $\mathrm{Ca}$ in the samples was from $\mathrm{CaCO}_{3}$ and thus allowed the use of the $\mathrm{Ca}$ concentration as a proxy.

\section{Quality control}

Calcium contents in those samples for which triplicates existed (original method) were generally in excellent agreement, demonstrating the reproducibility of $\mathrm{CaCO}_{3}$ extraction (Table A.2, SI). Furthermore, calcium contents in the aqua regia digest compared to the sum of the five extractions steps were generally below $10 \%$ (Tables A.2 and A.3, S1). Those results confirmed the suitability to extract the entire $\mathrm{CaCO}_{3}$ from the sediments in step 2.

\section{Assessment of reagent volumes}

To optimize the sequential extraction procedure for high $\mathrm{CaCO}_{3}$ samples, it was necessary to extract the $\mathrm{CaCO}_{3}$ entirely in extraction step 2 . Results obtained with the original extraction procedure showed substantial amounts of Ca present in fractions 2, 3, and 4 (Fig. 1A-F, $5 \mathrm{~mL}$ ). A closer look revealed that the sample with the lowest amount of Ca (C-68, Fig. 1D, $5 \mathrm{~mL}$ ) had only little $\mathrm{Ca}$ left in fraction 4 , whereas the samples higher in $\mathrm{CaCO}_{3}$ still had larger amounts of Ca in step 4.

Increasing the amount of reagent in extraction step 2 increased the amount of dissolved $\mathrm{Ca}$ in this step (Fig. 1A-F). A reagent volume of $20 \mathrm{~mL}$ caused a more or less complete extraction of $\mathrm{Ca}$ in step 2 and nearly no more $\mathrm{Ca}$ in steps 3 and 4 . That observation was identical for both reagents, $\mathrm{Na}$-acetate and $\mathrm{NH}_{4}$-acetate.

Calcium contents in the extractions made with $\mathrm{Na}$ - and $\mathrm{NH}_{4}$-acetate in extraction steps 1 and 2 were comparable 

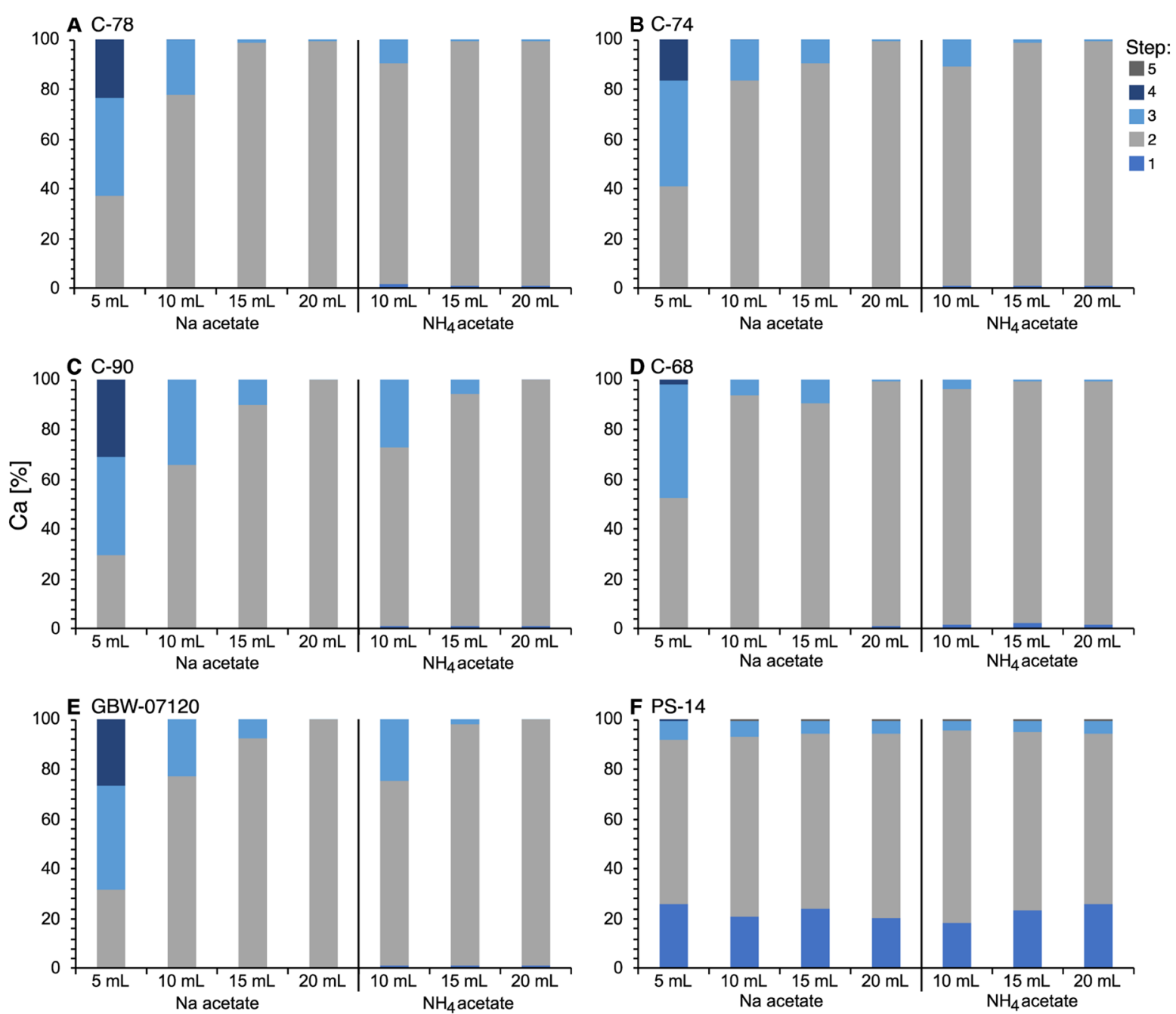

Fig. $1 \mathrm{Ca}(\%)$ in extraction steps 1 to 5 for the original $(5 \mathrm{~mL} \mathrm{NaOAc})$ and modified sequential extraction procedures $(10,15$, and 20 $\mathrm{mL}$, both $\mathrm{NaOAc}$ and $\mathrm{NH}_{4} \mathrm{OAc}$ )

for the same reagent volume (Fig. 1A-F; Table A.3, SI), although the amount of $\mathrm{Ca}$ in step 1 was slightly higher when using $\mathrm{NH}_{4}$-acetate (Table A.3, SI). A similar observation was made for Mg. However, during ICP-OES analyses, intensities were by up to $50 \%$ higher when using $\mathrm{NH}_{4}$-acetate instead of Na-acetate in steps 1 and 2 (see "Discussion").

Substantial amounts of $\mathrm{Mn}$ were found in steps 3 to 5 when the original extraction procedure was used (Fig. 2A-F). Similar to $\mathrm{Ca}$, Mn was dissolved in extraction step 2 when increasing $\mathrm{Na}$-acetate and $\mathrm{NH}_{4}$-acetate. In contrast to $\mathrm{Ca}$, some samples (C-90, GBW) had some Mn left in step 3 in the adjusted protocol, while others showed complete removal of $\mathrm{Mn}$ in step 2 after increasing the reagent volume to 15 or $20 \mathrm{~mL}$ (C-78, C-74). For the Posidonia shale, we observed a slight increase of $\mathrm{Mn}$ in step 2 with the adjusted extraction procedure; however, there was no difference whether $10 \mathrm{~mL}, 15$ $\mathrm{mL}$, or $20 \mathrm{~mL}$ of reagent was used.

Iron $(\mathrm{Fe})$ was used to assess if the dissolution of hydrous and crystalline iron oxides happened due to the increased reagent to sample ratio in extraction step 2. However, Fe proved to be of limited use because its concentration in the samples was often below the detection limit in some of the extraction steps (Tables A.2-A.5, SI). 

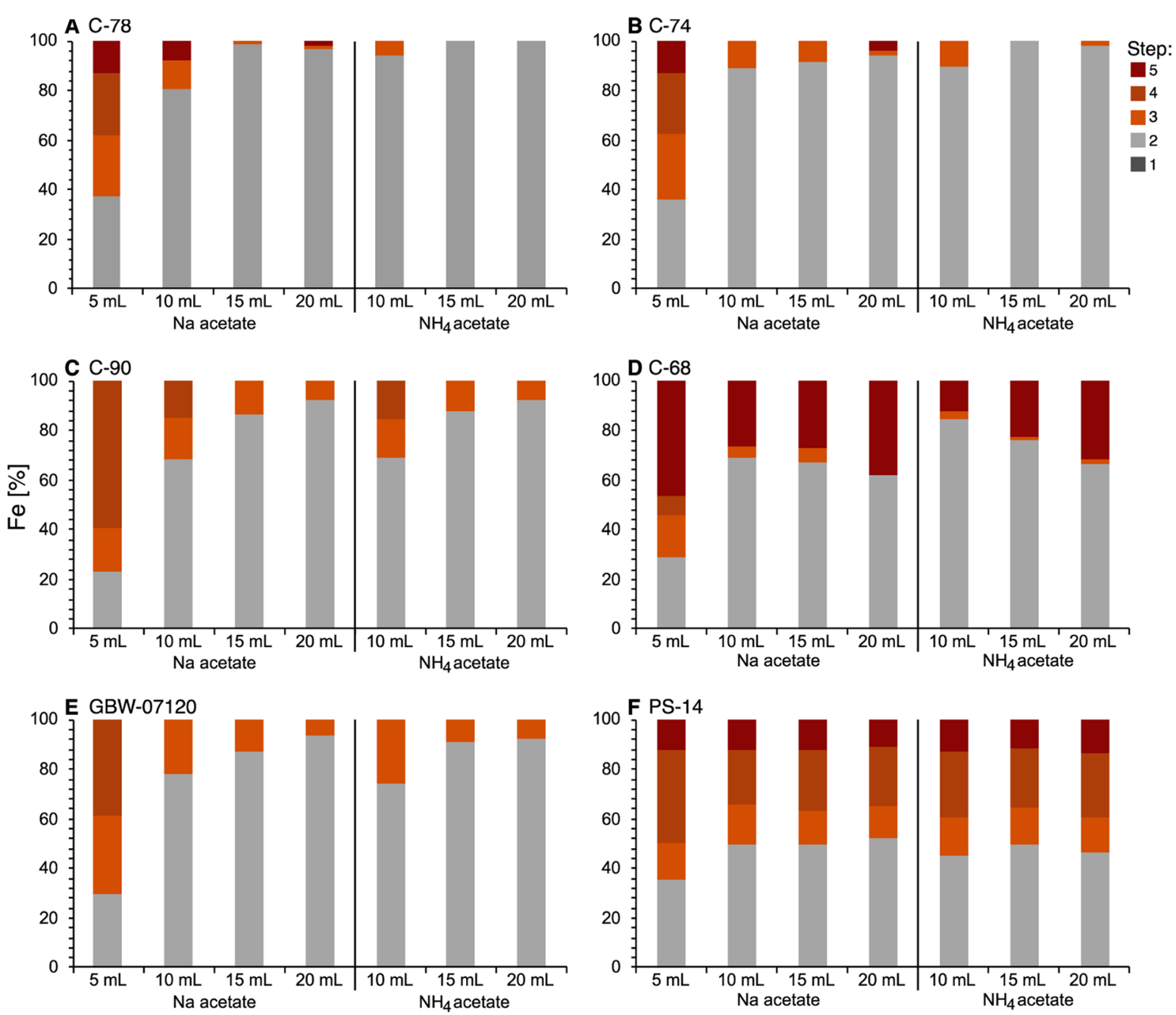

Fig. $2 \mathrm{Mn}(\%)$ in extraction steps 1 to 5 for the original $(5 \mathrm{~mL} \mathrm{NaOAc})$ and modified sequential extraction procedures (10, 15, and $20 \mathrm{~mL}$, both $\mathrm{NaOAc}$ and $\mathrm{NH}_{4} \mathrm{OAc}$ )

The Posidonia shale sample (PS-14, Fig. 3F) had enough Fe extracted in steps 3 and 4 to allow detection and showed no Fe increase in extraction step 2 when increasing the reagent volume (Tables A.3-A.5, SI).

Molybdenum (Mo) was almost entirely dissolved in extraction step 1 (Tables A.2 and A.3, SI). In contrast, the As content in most samples was too low to be determined, except for sample C-68 $(61 \mathrm{mg} / \mathrm{kg})$, where As was detected mostly in extraction step 1 and to some smaller extent in extraction step 2 (Tables A.2 and A.3, SI). Furthermore, we observed no difference in Mo and As contents with respect to the reactant to sample ratio. The Posidonia shale
(PS-14) had no measurable As, and the Mo content was $32 \mathrm{mg} / \mathrm{kg}$, most of which was found in extraction step 4. For Mo and As, we did not observe any difference between extractions done with $\mathrm{Na}$-acetate and $\mathrm{NH}_{4}$-acetate (Table A.3, SI).

\section{Discussion}

Adjustment of the reagent to sample ratio for carbonate extraction in $\mathrm{CaCO}_{3}$-rich samples

Calcium carbonate $\left(\mathrm{CaCO}_{3}\right)$ calculated from $\mathrm{Ca}$ contents of the aqua regia digest agreed well with 
carbometer results and published values. Therefore, it was permissible to interpret $\mathrm{Ca}$ concentrations extracted in the individual extractions steps as representative for $\mathrm{CaCO}_{3}$. In sample C-74 (Fig. 1B), the $\mathrm{CaCO}_{3}$ concentration calculated from $\mathrm{Ca}$ was slightly higher $(81 \%)$ than the carbometer result (74\%), potentially resulting from the presence of $\mathrm{Ca}$ in mineral phases other than $\mathrm{CaCO}_{3}$. Since we observed complete removal of $\mathrm{Ca}$ in extraction step 2 in the optimized method (Table A.3, SI), the excess $\mathrm{Ca}$ had to be present in a carbonate mineral, such as dolomite, which was not detectable with the calcium carbometer. While the dissolution of calcite occurs very fast in the carbometer, the dissolution of dolomite is slower and takes approximately 15 min (De Blasio et al., 2013; Stumm, 1990). According to Loring (1976), the complete dissolution of $\mathrm{CaCO}_{3}$ is based on several factors such as the grain size, total carbonate content, and carbonate type. Since the samples in this study had the same grain size and similar carbonate content, only the carbonate type should have made a difference. In PS-14 (Fig. 1F), Ca extracted in extraction step 2 (resulting in $\left.13 \% \mathrm{CaCO}_{3}\right)$ agreed with the carbometer results $(14 \%)$, whereas the aqua regia-based bulk $\mathrm{Ca}$ overestimated the carbonate content (23\%). Actual extraction of $\mathrm{Ca}$ in step 1 suggested the presence of adsorbed $\mathrm{Ca}$ in addition to carbonate-bound Ca.

As seen in Fig. 1A-F, the extraction using the original sequential extraction procedure (Hall et al., 1996; Pichler et al., 2001) caused incomplete extraction of $\mathrm{Ca}$ in step 2 and substantial amounts of $\mathrm{Ca}$ in extraction steps 3 and 4. Similar results were observed by Davidson et al. (2006) during sequential extraction analyses of urban soils using the optimized BCR method (Rauret et al., 1999). They showed that in high-carbonate samples $(>30$ $\left.\% \mathrm{CaCO}_{3}\right), \mathrm{CaCO}_{3}$ was not entirely dissolved by $0.11 \mathrm{~mol} \mathrm{~L}^{-1}$ acetic acid, resulting in a $\mathrm{pH}$ increase in the next extraction step, and thus impeding the extraction in the next step (Davidson et al., 2006).

Interestingly, in our study, the amount of $\mathrm{Ca}$ extracted in extraction step 2 was roughly the same $\left(\sim 100,000 \mathrm{mg} / \mathrm{kg}\right.$ ) for all $\mathrm{CaCO}_{3}$ samples (Table A.2, $\mathrm{SI})$. Assuming the $\mathrm{Ca}$ in this to be entirely derived from $\mathrm{CaCO}_{3}$ resulted in approximately 26 to 27 weight- $\% \mathrm{CaCO}_{3}$ extracted. In relatively low $\mathrm{CaCO}_{3}$ samples, such as sample $\mathrm{C}-68$, this resulted in the dissolution of nearly half of the $\mathrm{CaCO}_{3}$ in extraction step 2. In contrast, in those samples with a higher $\mathrm{CaCO}_{3}$ content (> $80 \%$ ), only approximately onethird was extracted. That confirmed the limitation of the method and the need to optimize the original sequential extraction procedure to remove the entire $\mathrm{CaCO}_{3}$ in extraction step 2 .

To improve extraction in step 2, we modified the reagent to sample ratio but kept the other steps (including step 1) unchanged. Based on the results from the original sequential extraction procedure, it was assumed that increasing the reagent would cause a more complete extraction of $\mathrm{CaCO}_{3}$ in step 2. While there was already a significant increase in extraction efficiency for $\mathrm{Ca}$ in step 2 using $10 \mathrm{~mL}$ and $15 \mathrm{~mL}$ of Na-acetate and $\mathrm{NH}_{4}$-acetate solution, we observed nearly complete removal of $\mathrm{Ca}$ in step 2 when adding $20 \mathrm{~mL}$ of the extracting reagent (Fig. 1A-F). This is supported by complete dissolution of pure calcium carbonate (Carl Roth, Germany) when using $20 \mathrm{~mL}$ extraction solution (not shown). Our results indicated that increasing the reagent to sample ratio by a factor of 4 compared to what has been suggested for standard samples was a good starting point for investigating the correct amount of reagent needed. Nevertheless, it seemed appropriate to carefully determine the proper amount of reagent required for the sample matrix under investigation. Another possible approach would have been a repetition of the carbonate removal step to dissolve all carbonates, as was done in a previous study (Sulkowski \& Hirner, 2006). While this would have had the advantage of using more sediment with the available equipment (see section "Adjustments to the sequential extraction procedure"), we omitted this procedure to avoid possible sediment loss while decanting the extracting solution between the individual steps.

Manganese $(\mathrm{Mn})$ was expected to be present as a minor element in $\mathrm{CaCO}_{3}$ or as rhodochrosite $\left(\mathrm{MnCO}_{3}\right)$. Fig. 2A-F show that the extraction of $\mathrm{Mn}$ was not as systematic as the extraction of $\mathrm{Ca}$. We observed a clear trend of increasing $\mathrm{Ca}$ concentration in step 2 when increasing the reagent volume, resulting in a complete carbonate removal in step 2 with 20 $\mathrm{mL}$ reagent. In contrast, some Mn was present in the extracts from step 3, particularly those with carbonate contents $>80 \%$ (C-90, GBW). One reason might be the incomplete dissolution of Mn-carbonates in these samples. Another possibility could have been the 
presence of a small amount of other Mn phases, e.g., Mn oxides. Because in those two samples, the amount of $\mathrm{Mn}$ in step 3 decreased with an increasing amount of reagent, we rejected the latter and assumed incomplete removal of Mn carbonates. The results suggest that further increasing the reagent to samples ratio would result in complete Mn carbonate dissolution in these samples.

An important observation was that increasing the volume of reagent in step 2 did not compromise the subsequent extraction steps by attacking hydrous and crystalline Fe oxides or sulfides already in step 2. While most samples used in this study had relatively low $\mathrm{Fe}$ concentrations, the Posidonia shale sample
(PS-14) demonstrated that a large reagent volume in step 2 did not cause larger amounts of $\mathrm{Fe}$ in extraction step 2 (Tables A.3-A.5, S1). In particular, the detailed study of sample PS-14, in which all reagent to sample ratios were covered, clearly showed no effect of the increased reagent to sample ratios on Fe concentrations (Fig. 3F). For Fe and $\mathrm{Mg}$ in the carbonate samples, it was noticeable that the sum did not match the aqua regia digestions exactly. We suspected that this was due to the relatively small amount of material used for the extractions ( $0.25 \mathrm{~g})$, which likely caused sample inhomogeneity and an increased risk of sediment loss due to the transfer between extraction steps. We, therefore, recommend choosing a larger amount
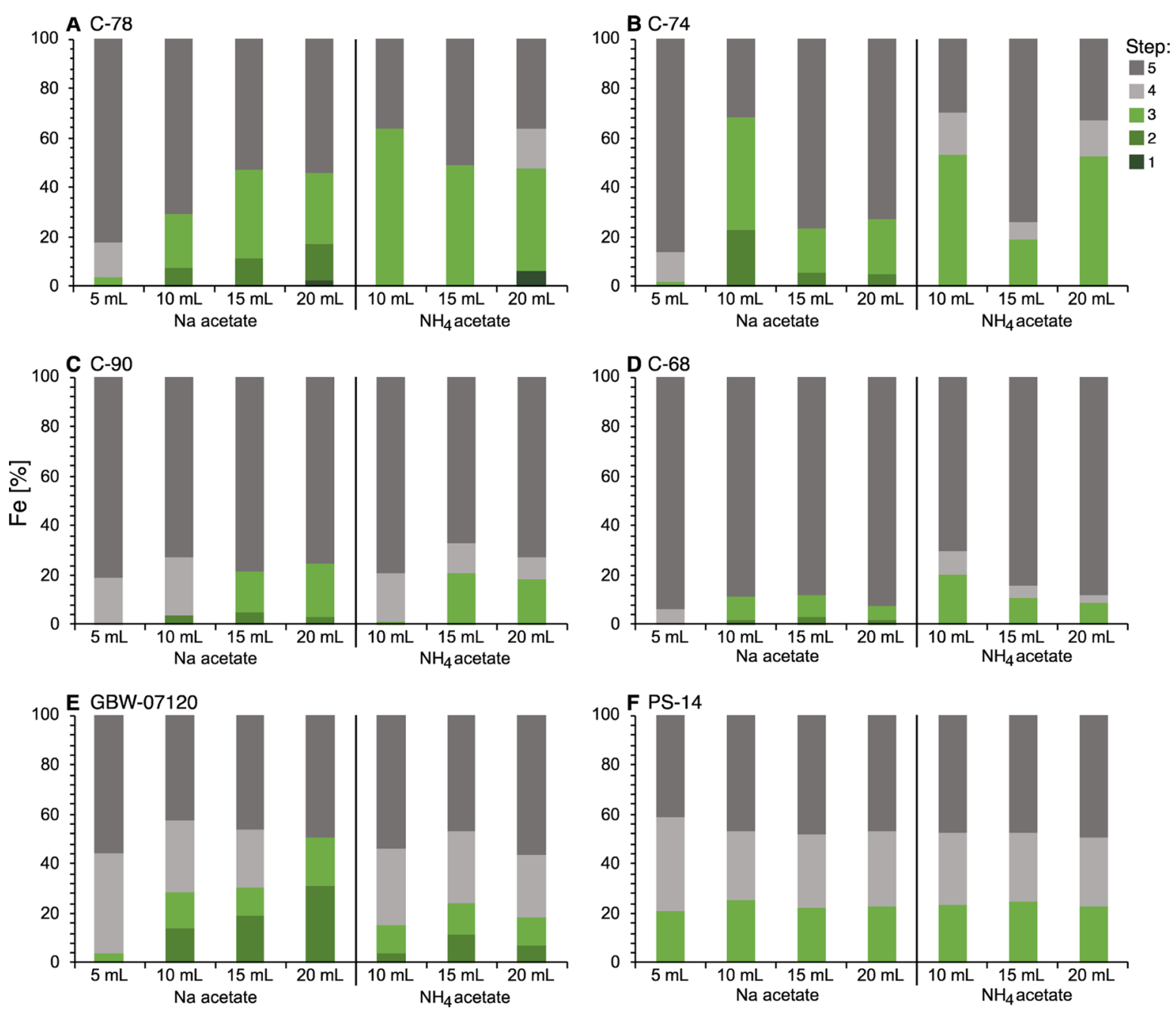

Fig. $3 \mathrm{Fe}(\%)$ in extraction steps $1-5$ for original $(5 \mathrm{~mL}, \mathrm{NaOAc})$ and modified sequential extraction procedure $(10,15$, and $20 \mathrm{~mL}$, both $\mathrm{NaOAc}$ and $\mathrm{NH}_{4} \mathrm{OAc}$ ) in all samples 
of sediment material and corresponding solvent amount if possible. However, a critical result from this study was that due to incomplete carbonate dissolution in step 2 using the original procedure, the extraction of hydrous and crystalline iron was inhibited, as seen in low Fe in steps 3 and 4 (Fig. 3A-E). The modified extraction procedure, which fully dissolved carbonates in step 2, allows the extraction of these phases in designated steps 3 and 4 .

Na-acetate vs. $\mathrm{NH}_{4}$-acetate extraction

Both reagents, Na- and $\mathrm{NH}_{4}$-acetate, delivered a similar extraction efficiency for $\mathrm{Ca}$ and $\mathrm{Mn}$ in step 2. While Naacetate, as well as $\mathrm{NH}_{4}$-acetate, was used extensively for the extraction of adsorbed/exchangeable and carbonate phases (e.g., Gleyzes et al., 2001; Tessier et al., 1979), the typical extractant for the carbonate phase was $\mathrm{Na}-$ acetate buffered to a pH of 5 (e.g., Gleyzes et al., 2001; Pickering, 1986). Because dissolution of carbonate is achieved by reaction with $\mathrm{H}^{+}$(Gleyzes et al., 2002), it is not surprising that $\mathrm{Na}$-acetate and $\mathrm{NH}_{4}$-acetate, both adjusted to a $\mathrm{pH}$ of 5, dissolve the same amounts of $\mathrm{Ca}$ (i.e., carbonate) in extraction step 2. Concerning extraction step 1, several studies showed that an $\mathrm{NH}_{4}$-acetate solution at a $\mathrm{pH}$ of 7.0 is a suitable solvent for releasing the adsorbed/exchangeable fraction, although it was suspected to react with the carbonate fraction (Chapman, 1965; Jackson, 1958; Tessier et al., 1979 \& references therein; Wagemann et al., 1977). While this may explain higher $\mathrm{Ca}$ values in the first extraction step using $\mathrm{NH}_{4}$-acetate compared to Na-acetate, absolute concentrations of $\mathrm{Ca}$ in extraction step 1 and differences between

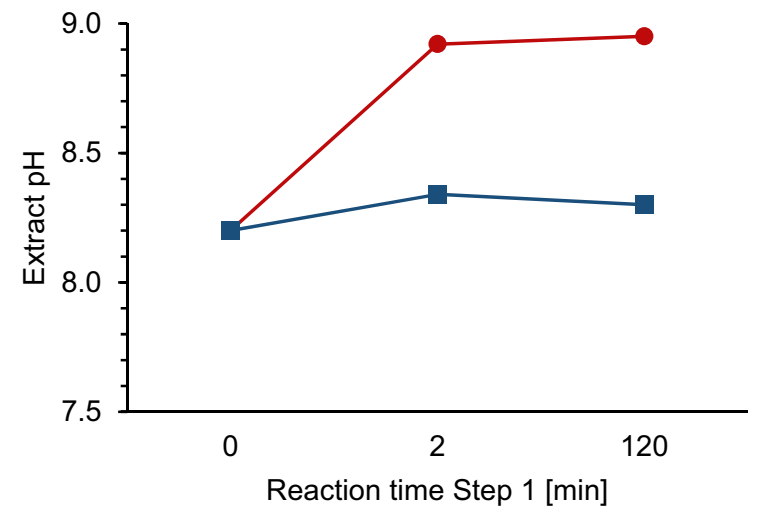

Fig. 4 Changes in $\mathrm{pH}$ values in extraction steps 1 and 2 for pure $\mathrm{CaCO}_{3}$. The $\mathrm{pH}$ value was adjusted to 8.2 and 5.0, respectively, in the extraction solutions $(0 \mathrm{~min})$ measured after the
$\mathrm{Na}$ - and $\mathrm{NH}_{4}$-acetate are too low to compromise the results for the high-carbonate samples used in this study (Table A.3, SI). However, to lower the potential for dissolution of $\mathrm{CaCO}_{3}$, we did not use $\mathrm{NH}_{4}$-acetate at a $\mathrm{pH}$ of 7, as discussed in Tessier et al. (1979), but adjusted the $\mathrm{pH}$ to 8.2 (as for Na-acetate). It was reported that the extraction of $\mathrm{Ca}$ from limestone starts at $\mathrm{pH}<8.1$ (Carrow \& Duncan, 2011), which supported the use of a $\mathrm{pH}$ of 8.2. In summary, even if it was not possible to exclude any attack of carbonates by $\mathrm{NH}_{4}$-acetate entirely, there was no significant effect, which could compromise interpretations. Nevertheless, the use of $\mathrm{NH}_{4}$-acetate as a reagent in the first extraction step should be considered carefully for the sequential extraction of materials with less carbonate content. Monitoring the $\mathrm{pH}$ in pure $\mathrm{CaCO}_{3}$ (Carl Roth, Germany) during extraction steps 1 and 2 showed that the $\mathrm{pH}$ in the $\mathrm{NH}_{4}$-acetate solution increased only slightly in step 1 . In contrast, it increased from 8.20 to 8.95 in Na-acetate (Fig. 4). That indicated that the system was buffered less in the Na-acetate solution in step 1.

While there was no advantage of $\mathrm{NH}_{4^{-}}$over $\mathrm{Na}$ acetate as a reagent during the extraction, the real benefit of using $\mathrm{NH}_{4}$-acetate became apparent during the chemical analyses of the extracts. It is wellknown that in ICP-OES analyses, the presence of $\mathrm{Na}$ ions can suppress the analyte intensities of several elements (e.g., Brenner et al., 1999; Brenner et al., 1997; Ivaldi \& Tyson, 1995). Accordingly, during our preliminary tests for the analysis of Mo and As, we observed approximately $20 \%$ (As) and $35 \%$ (Mo) higher intensities using $0.33 \mathrm{M} \mathrm{NH}_{4}$-acetate compared to $0.33 \mathrm{M} \mathrm{Na-acetate} \mathrm{(Fig.} \mathrm{5).} \mathrm{Hence,}$ the use of $\mathrm{NH}_{4}$-acetate in extractions steps 1 and 2

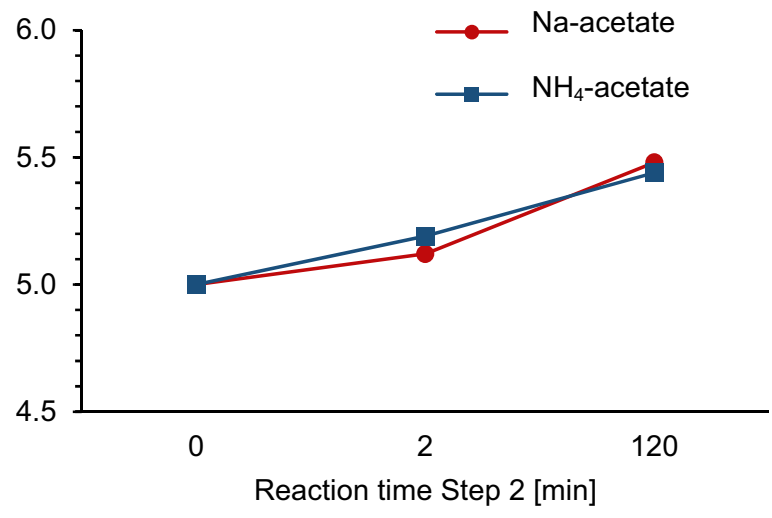

addition to the extracts ( $2 \mathrm{~min}$ ) and at the end of the reaction $(120 \mathrm{~min})$. Note that the $\mathrm{x}$-axis is not on a linear scale 


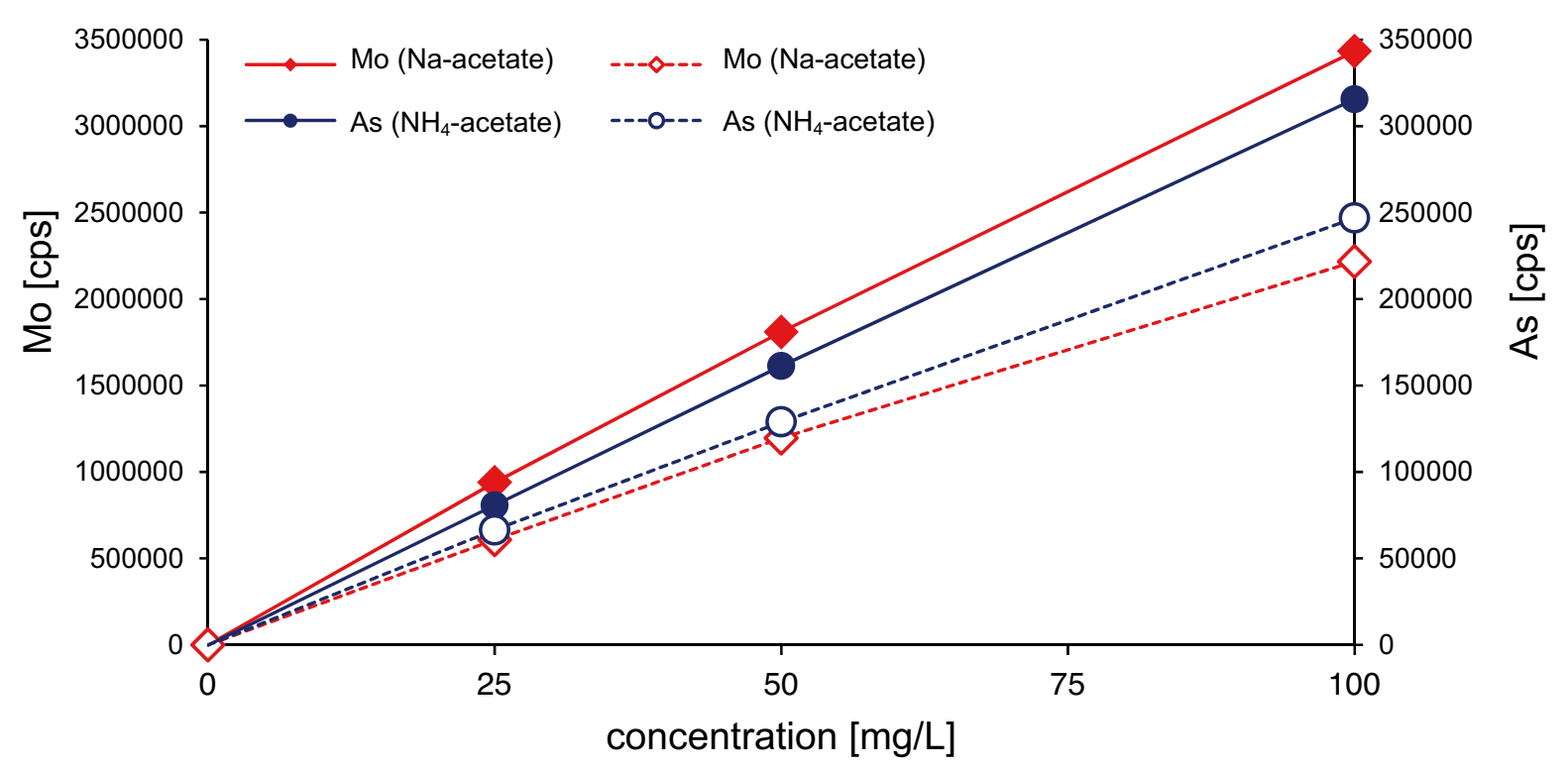

Fig. 5 Intensities in counts per second (cps) for Mo and As during ICP-OES analysis in $0.33 \mathrm{M} \mathrm{NH}_{4}$-acetate and Na-acetate

prevented signal suppression by $\mathrm{Na}$. While signal intensities were not an issue for major elements such as $\mathrm{Ca}, \mathrm{Mg}$, and sometimes $\mathrm{Fe}$ or $\mathrm{Mn}$, trace metals released during sequential extraction steps often had concentrations close to or below the limit of detection by ICP-OES. For these elements, signal enhancement by 20 to $35 \%$ can be decisively important.

Extraction efficiency for Mo and As

Most samples used in this study were from the Floridan Aquifer System where As and Mo are known contaminants (e.g., Lazareva \& Pichler, 2007;
Pichler \& Mozaffari, 2015); and thus, both were included in the suite of analytes. Molybdenum and As were almost wholly extracted in step 1 . While this was a systematic observation for Mo in the carbonate samples, we had only one sample with sufficient As, C-68. While the results were comparable, the use of $\mathrm{NH}_{4}$-acetate compared to $\mathrm{Na}$-acetate produced stable concentrations for the complete extraction procedure regardless of the amount of reagent used in step 2 (Fig. 6). The larger variations for the extractions of As with Na-acetate in steps 2 and 3 were in part owed to the low concentrations, which favored the
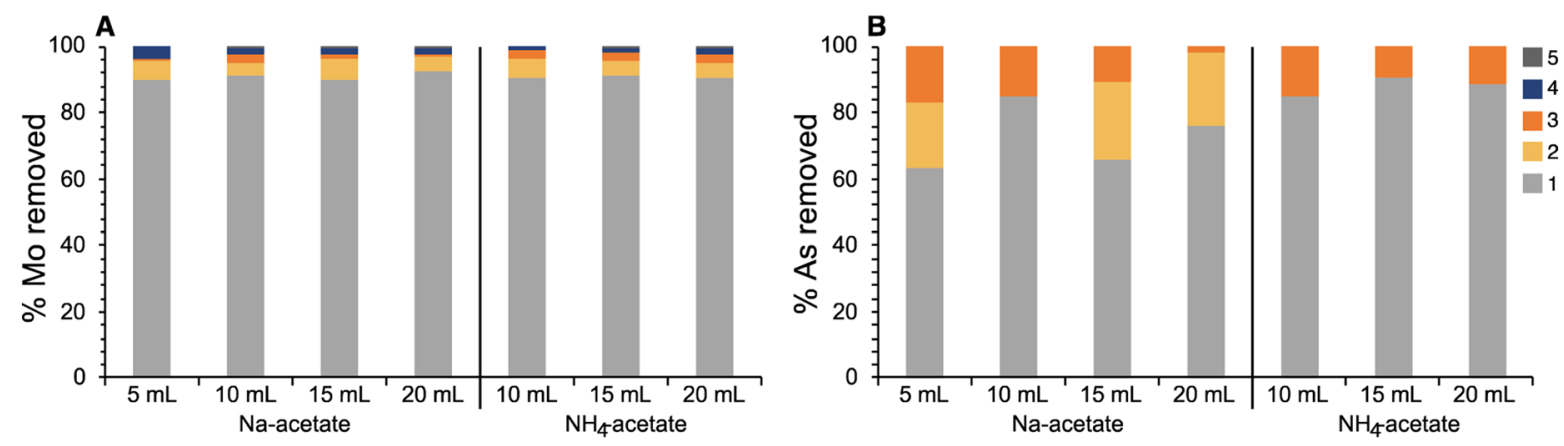

Fig. 6 Portions of Mo and As removed in extraction steps 1-5 for the original ( $5 \mathrm{~mL}$ NaOAc) and modified sequential extraction procedure in sample C-68. As shows higher fluctuations than Mo due to low concentrations in steps 2-5 
Fig. 7 Portions of Mo removed in extraction steps 1 to 5 for the original ( 5 $\mathrm{mL} \mathrm{NaOAC)}$ and modified sequential extraction procedures (remaining) in sample PS-14

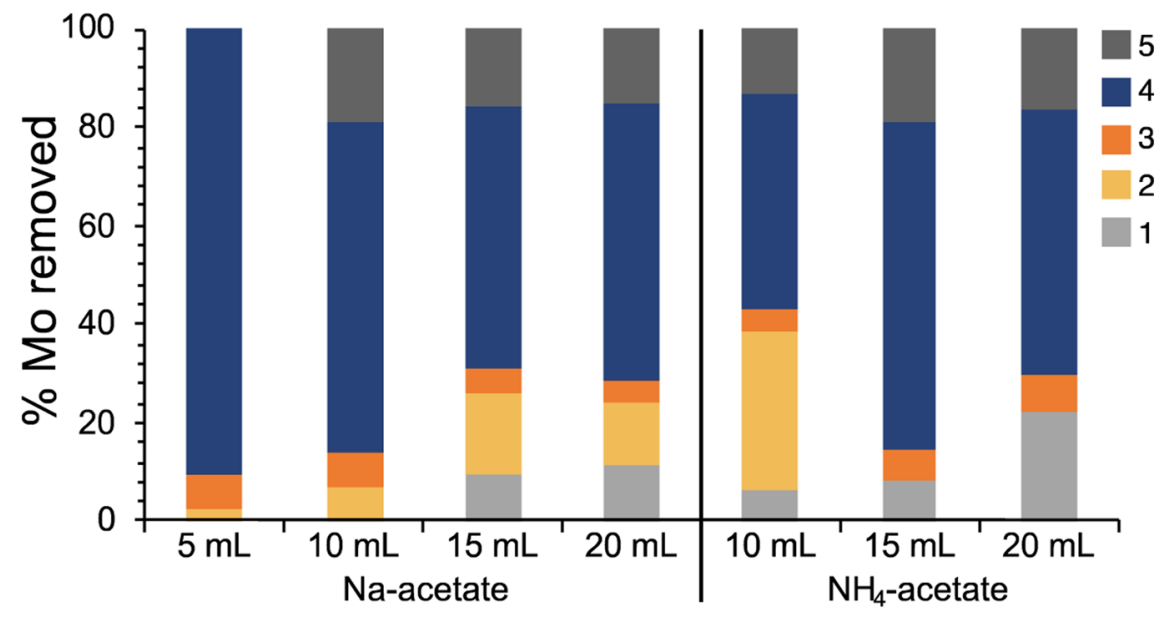

$\mathrm{NH}_{4}$-acetate extracts due to their analytical advantage (see above).

Molybdenum adsorbs as molybdate $\left(\mathrm{MoO}_{4}{ }^{2-}\right)$ or thiomolybdate $\left(\mathrm{MoO}_{\mathrm{n}} \mathrm{S}_{4-\mathrm{n}}{ }^{2-}\right)$ onto oxides (Fe, $\mathrm{Mn}$, $\mathrm{Al}, \mathrm{Ti}$ ), pyrite, organic matter, and clay minerals, depending on the geochemical conditions (Bibak \& Borggaard, 1994; Goldberg et al., 1996; Smedley \& Kinniburgh, 2017; Xu et al., 2013). Arsenic adsorbs as arsenite $\left(\mathrm{As}^{3+}\right)$ and arsenate $\left(\mathrm{As}^{5+}\right)$ onto oxides (Fe, $\mathrm{Mn}, \mathrm{Al}$ ), clay minerals, and the surface of calcite (Smedley \& Kinniburgh, 2002). The fact that both elements were observed to be mostly extracted in step 1 in the original extraction procedure suggested that the low reagent to sample ratio used in this approach was enough to release the adsorbed/ exchangeable Mo and As from the solid phase. Those results agreed with what was found by Pichler and Mozaffari (2015).

In sample PS-14, which was not a carbonate sediment but had a $\mathrm{CaCO}_{3}$ of $14 \%$, Mo was mainly bound in the sulfide/organic matter fraction (Table A.3, SI; Fig. 7) as expected for TOC and pyrite-rich samples (e.g., Brumsack, 1991; Chappaz et al., 2014). An increase in the amount of reagent in step 2 did not affect the extraction of Mo contents in the following steps, an observation similar to what was seen for Fe (Fig. 3F). Thus, we concluded that the higher reagent to sample ratio did not affect Mo extraction, even in samples with low $\mathrm{CaCO}_{3}$ contents. That observation is of particular importance for using the same extraction procedure for extraction studies concerning samples with a wide range of $\mathrm{CaCO}_{3}$ concentrations.

\section{Conclusions}

Our study demonstrated the need to adjust sequential extraction procedures to the research objectives and matrix requirements.

High- $\mathrm{CaCO}_{3}$ samples need more volume of reagent in the 2nd extraction step. Even with lower amounts of $\mathrm{CaCO}_{3}$ (see PS-14), the method is applicable. There is no need to adjust the method for samples with lower $\mathrm{CaCO}_{3}$ contents within a set of samples with different $\mathrm{CaCO}_{3}$ contents. An incomplete dissolution of $\mathrm{CaCO}_{3}$ in step 2 causes leftover $\mathrm{CaCO}_{3}$ in the subsequent steps, which prevents the dissolution of designated phases in these steps, namely hydrous and crystalline oxides. The adjusted protocol thus improves the extraction of oxide phases in the later extraction steps. A larger amount of extraction reagent in step 2 does not compromise following extractions steps, i.e., we observed no enhanced dissolution of Fe or Mo in step 2. $\mathrm{NH}_{4}$-Acetate can replace Na-acetate in extraction steps 1 and 2 to reduce $\mathrm{Na}$ interference in the plasma during ICPOES measurements, which can be of particular importance for studying trace metals, such as As and Mo.

Acknowledgements We are grateful to Wintershall Dea $\mathrm{GmbH}$ for providing the Posidonia shale sample with special thanks to Thorsten Lippner for his support during sampling. We thank Brit Kockisch (Universität Bremen) for help with carbometer analysis and Kay Hamer (Universität Bremen) for helpful discussions. We thank three anonymous reviewers for their constructive comments, which improved this manuscript. We further thank M. V. Esteller for editorial handling. 
Author contribution Scheplitz carried out the experiments and participated in study design, and wrote the first rough draft. Koopmann and Fröllje participated in study design, supervised experiments, and edited first draft. Pichler conceptualized the study, supervised study design, and edited the final draft.

Funding Open Access funding enabled and organized by Projekt DEAL. This study was funded by the Deutsche Forschungsgemeinschaft (DFG) through grant PI 746/11-1 to Pichler.

Availability of data and materials All data generated or analyzed during this study are included in this published article (and its supplementary information files).

\section{Declarations}

Competing interests The authors declare no competing interests.

Open Access This article is licensed under a Creative Commons Attribution 4.0 International License, which permits use, sharing, adaptation, distribution and reproduction in any medium or format, as long as you give appropriate credit to the original author(s) and the source, provide a link to the Creative Commons licence, and indicate if changes were made. The images or other third party material in this article are included in the article's Creative Commons licence, unless indicated otherwise in a credit line to the material. If material is not included in the article's Creative Commons licence and your intended use is not permitted by statutory regulation or exceeds the permitted use, you will need to obtain permission directly from the copyright holder. To view a copy of this licence, visit http://creativecommons.org/licenses/by/4.0/.

\section{References}

Aydin, I., Aydin, F., \& Hamamci, C. (2012). Molybdenum speciation in asphaltite bottom ash (Seguruk, SE Anatolia, Turkey). Fuel, 95, 481-485. https://doi.org/10.1016/j.fuel. 2011.09.013

Bibak, A., \& Borggaard, O. K. (1994). Molybdenum adsorption by aluminium and iron oxides and humic acid. Soil Science, 158, 323-328.

Brenner, I. B., Le Marchand, A., Daraed, C., \& Chauvet, L. (1999). Compensation of $\mathrm{Ca}$ and $\mathrm{Na}$ interference effects in axially and radially viewed inductively coupled plasmas. Microchemical Journal, 63, 344-355. https://doi.org/10. 1006/mchj.1999.1800

Brenner, I. B., Zander, A., Cole, M., \& Wiseman, A. (1997). Comparison of axially and radially viewed inductively coupled plasmas for multi-element analysis: Effect of sodium and calcium. Journal of Analytical Atomic Spectrometry, 12, 897-906. https://doi.org/10.1039/a700465f

Brumsack, H. J. (1991). Inorganic geochemistry of the German "Posidonia Shale": palaeoenvironmental consequences. Geological Society, London, Special Publications, 58, 353-362.
Carrow, R. N., \& Duncan, R. R. (2011). Best management practices for saline and sodic turfgrass soils: Assessment and reclamation. CRC Press.

Chapman, H. (1965). Cation-exchange capacity. Methods of Soil Analysis: Part 2 Chemical and Microbiological Properties, 9, 891-901.

Chappaz, A., Lyons, T. W., Gregory, D. D., Reinhard, C. T., Gill, B. C., Li, C., \& Large, R. R. (2014). Does pyrite act as an important host for molybdenum in modern and ancient euxinic sediments? Geochimica et Cosmochimica Acta, 126, 112-122. https://doi.org/10.1016/j.gca.2013.10.028

Davidson, C. M., et al. (2006). Fractionation of potentially toxic elements in urban soils from five European cities by means of a harmonised sequential extraction procedure. Analytica Chimica Acta, 565, 63-72.

De Blasio, C., Carletti, C., Westerlund, T., Järvinen, M. (2013). On the reactivity of carbonate rocks utilized in wet flue gas desulfurization: Modeling the reaction kinetics of solid particles by a step-wise titration method with turbulent conditions. Paper presented at the International Conference on Applied Energy ICAE 2013. Pretoria, South Africa.

Filgueiras, A., Lavilla, I., \& Bendicho, C. (2002). Chemical sequential extraction for metal partitioning in environmental solid samples. Journal of Environmental Monitoring JEM, 4, 823-857. https://doi.org/10.1039/B207574C

Ford, D., \& Williams, P. (2007). Introduction to Karst. In: Karst Hydrogeology and Geomorphology (pp 1-8). https://doi. org/10.1002/9781118684986.ch1

Gleyzes, C., Tellier, S., \& Astruc, M. (2002). Fractionation studies of trace elements in contaminated soils and sediments: A review of sequential extraction procedures. Trends in Analytical Chemistry, 21, 451-467.

Gleyzes, C., Tellier, S., Sabrier, R., \& Astruc, M. (2001). Arsenic characterisation in industrial soils by chemical extractions. Environmental Technology, 22, 27-38. https://doi. org/10.1080/09593332208618313

Goldberg, S., Forster, H. S., \& Godfrey, C. L. (1996). Molybdenum adsorption on oxides, clay minerals, and soils. Soil Science, 60, 425-432.

Goldscheider, N., et al. (2020). Global distribution of carbonate rocks and karst water resources. Hydrogeology Journal, 28, 1661-1677. https://doi.org/10.1007/s10040-020-02139-5

Hall, G. E. M., Vaive, J. E., Beer, R., \& Hoashi, M. (1996). Selective leaches revisited, with emphasis on the amorphous Fe oxyhydroxide phase extraction. Journal of Geochemical Exploration, 56, 59-78.

Ivaldi, J. C., \& Tyson, J. F. (1995). Performance evaluation of an axially viewed horizontal inductively coupled plasma for optical emission spectrometry. Spectrochimica Acta Part B: Atomic Spectroscopy, 50, 1207-1226. https://doi. org/10.1016/0584-8547(95)01330-h

Jackson, M. (1958). Soil chemical analysis prentice Hall Inc. Englewood Cliffs, NJ, 498, 183-204.

Jones, G. W., \& Pichler, T. (2007). The relationship between pyrite stability and arsenic mobility during aquifer storage and recovery in Southwest Central Florida. Environmental Science and Technology, 41, 723-730.

Katz, B. G. (2004). Sources of nitrate contamination and age of water in large karstic springs of Florida. Environmental Geology, 46, 689-706. https://doi.org/10.1007/S00254-004-1061-9 
Katz, B. G., McBride, W. S., Hunt, A. G., Crandall, C. A., Metz, P. A., Eberts, S. M., \& Berndt, M. P. (2009). Vulnerability of a public supply well in a Karstic aquifer to contamination. Ground Water, 47, 438-452.

Keon, N. E., Swartz, C. H., BraBander, D. J., Harvey, C., \& Hemond, H. F. (2001). Validation of an arsenic sequential extraction method for evaluating mobility in sediments. Environmental Science and Technology, 35, 2778-2784.

Koopmann, S., Fröllje, H., Hamer, K., Kubier, A., \& Pichler, T. (2019). Iron-manganese-anomalies of groundwater - analysis of influencing processes. Grundwasser, 25, 113-126. https:// doi.org/10.1007/s00767-019-00434-x

Lazareva, O., Druschel, G., \& Pichler, T. (2015). Understanding arsenic behavior in carbonate aquifers: Implications for aquifer storage and recovery (ASR). Applied Geochemistry, 52, 57-66.

Lazareva, O., \& Pichler, T. (2007). Naturally occurring arsenic in the Miocene Hawthorn Group, Southwestern Florida: Implication for phosphate mining. Applied Geochemistry, 22, 953-973.

Liang, L., \& Zhu, J.-M. (2016). An optimized sequential extraction scheme for molybdenum association in environmental samples Acta. Geochimica, 35, 111-119. https:// doi.org/10.1007/s11631-016-0096-4

Loring, D. (1976). The distribution and partition of zinc, copper, and lead in the sediments of the Saguenay Fjord. Canadian Journal of Earth Sciences, 13, 960-971.

McMahon, P. B., et al. (2008). Source and transport controls on the movement of nitrate to public supply wells in selected principal aquifers of the United States. Water Resources Research, 44, 17. https://doi.org/10.1029/2007wr006252

Miller, J. A. (1986). Hydrogeologic framework of the Floridan aquifer system in Florida, Georgia, South Carolina and Alabama.

Orsini, L., \& Bermond, A. (1993). Application of a sequential extraction procedure to calcareous soil samples: Preliminary studies. International Journal of Environmental Analytical Chemistry, 51, 97-108. https://doi.org/10.1080/ 03067319308027614

Pichler, T., Hendry, M. J., \& Hall, G. E. M. (2001). The mineralogy of arsenic in uranium mine tailings at the Rabbit Lake In-pit Facility, northern Saskatchewan, Canada. Environmental Geology, 40, 495-506.

Pichler, T., \& Mozaffari, A. (2015). Distribution and mobility of geogenic molybdenum and arsenic in a limestone aquifer matrix. Applied Geochemistry, 63, 623-633. https:// doi.org/10.1016/j.apgeochem.2015.08.006

Pichler, T., \& Veizer, J. (2004). The precipitation of aragonite from shallow-water hydrothermal fluids in a coral reef, Tutum Bay, Ambitle Island, Papua New Guinea. Chemical Geology, 207, 31-45.

Pichler, T., Price, R., Lazareva, O., \& Dippold, A. (2011). Determination of arsenic concentration and distribution in the Floridan Aquifer System. Journal of Geochemical Exploration, 111, 84-96.

Pichler, T., Renshaw, C. E., \& Sültenfuß, J. (2017). Geogenic As and Mo groundwater contamination caused by an abundance of domestic supply wells. Applied Geochemistry, 77, 68-79.

Pickering, W. F. (1986). Metal ion speciation - soils and sediments (a review). Ore Geology Reviews, 1, 83-146.
Price, R. E., \& Pichler, T. (2005). Distribution, speciation and bioavailability of arsenic in a shallow-water submarine hydrothermal system, Tutum Bay, Ambitle Island, PNG. Chemical Geology, 224, 122-135.

Quevauviller, P., et al. (1994). Evaluation of a sequential extraction procedure for the determination of extractable trace metal contents in sediments. Fresenius' Journal of Analytical Chemistry, 349, 808-814. https://doi.org/10. 1007/BF00323110

Rauret, G., López-Sánchez, J. F., Sahuquillo, A., Rubio, R., Davidson, C., Ure, A., \& Quevauviller, P. (1999). Improvement of the BCR three step sequential extraction procedure prior to the certification of new sediment and soil reference materials. Journal of Environmental Monitoring, 1, 57-61.

Romero, L., et al. (2003). Arsenic enrichment in waters and sediments of the Rio Loa (Second Region, Chile). Applied Geochemistry, 18, 1399-1416. https://doi.org/10.1016/ s0883-2927(03)00059-3

Smedley, P. L., \& Kinniburgh, D. G. (2002). A review of the source, behavior and distribution of arsenic in natural waters. Applied Geochemistry, 17, 517-568.

Smedley, P. L., \& Kinniburgh, D. G. (2017). Molybdenum in natural waters: A review of occurence, distributions and controls. Applied Geochemistry, 84, 387-432.

Stumm, W. (1990). Aquatic chemical kinetics - reaction rates of processes in natural waters. John Wiley \& Sons Inc.

Sulkowski, M., \& Hirner, A. V. (2006). Element fractionation by sequential extraction in a soil with high carbonate content. Applied Geochemistry, 21, 16-28.

Sutherland, R. A., \& Tack, F. M. G. (2002). Determination of $\mathrm{Al}, \mathrm{Cu}, \mathrm{Fe}, \mathrm{Mn}, \mathrm{Pb}$ and $\mathrm{Zn}$ in certified reference materials using the optimized BCR sequential extraction procedure. Analytica Chimica Acta, 454, 249-257.

Tessier, A., Campbell, P. G. C., \& Bisson, M. (1979). Sequential extraction procedure for the speciation of particulate trace metals. Analytical Chemistry, 51, 844-851. https:// doi.org/10.1021/ac50043a017

Ure, A. M., Quevauviller, P., Muntau, H., \& Griepink, B. (1993a). Speciation of heavy metals in soils and sediments. An account of the improvement and harmonization of extraction techniques undertaken under the auspices of the BCR of the Commission of the European Communities. International Journal of Environmental Analytical Chemistry, 51, 135-151. https://doi.org/10.1080/03067319308027619

Van Herreweghe, S., Swennen, R., Vandecasteele, C., \& Cappuyns, V. (2003). Solid phase speciation of arsenic by sequential extraction in standard reference materials and industrially contaminated soil samples. Environmental Pollution, 122, 323-342. https://doi.org/10.1016/S0269-7491(02)00332-9

Wagemann, R., Brunskill, G., \& Graham, B. (1977). Composition and reactivity of some river sediments from the Mackenzie Valley, NWT, Canada. Environmental Geology, 1, 349-358.

Wallis, I., \& Pichler, T. (2018). Generating false negatives and false positives for As and Mo concentrations in groundwater due to well installation. Science of The Total Environment, 631-632, 723-732. https://doi.org/10.1016/j.scitotenv.2018. 03.063

Wenzel, W. W., Kirchbaumer, N., Prohaska, T., Stingeder, G., Lombi, E., \& Adriano, D. C. (2001). Arsenic fractionation in soils using an improved sequential extraction procedure. Analytica Chimica Acta, 436, 309-323. 
WHO. (2011). Guidelines for drinking-water quality, 4th Edition. https://doi.org/10.1016/S1462-0758(00)00006-6

Xu, N., Braida, W., Christodoulatos, C., \& Chen, J. (2013). A review of molybdenum Adsorption in soils/bed sediments: Speciation, mechanism, and model applications. Soil and Sediment Contamination: An International Journal, 22, 912-929. https://doi.org/10.1080/15320383.2013.770438

Zemberyova, M., Hagarova, I., Zimova, J., Bartekova, J., \& Kuss, H. M. (2010). Determination of molybdenum in extracts of soil and sewage sludge CRMs after fractionation by means of BCR modified sequential extraction procedure. Talanta, 82, 582-586. https://doi.org/10.1016/j.talanta. 2010.05.010

Publisher's Note Springer Nature remains neutral with regard to jurisdictional claims in published maps and institutional affiliations. 